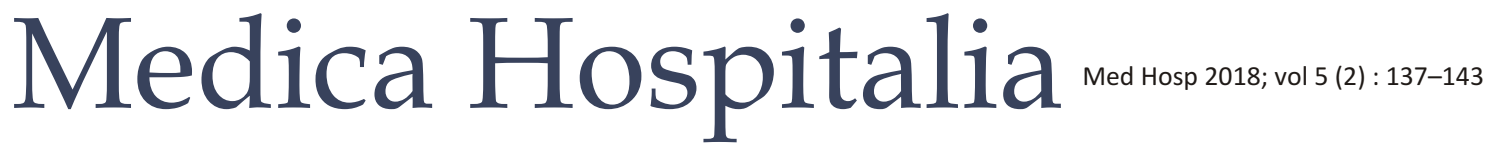

Case Report

\section{Tatalaksana Laringomalasia Kongenital Derajat Sedang pada Bayi}

\author{
Muyassaroh, Rery Budiarti \\ Bagian IKTHT-KL Fakultas Kedokteran Universitas Diponegoro / KSM KTHT-KL RSUP Dr. Kariadi Semarang \\ Abstrak

\section{Management of congenital laryngomalacia in infant patient}

\begin{abstract}
Latar belakang : Laringomalasia merupakan kelainan laring kongenital yang paling sering. Gejala khas laringomalasia adalah stridor inspirasi. Penatalaksanaan laringomalasia dengan non medikamentosa, medikamentosa dan operatif. Tujuan penulisan kasus ini adalah melaporkan tatalaksana laringomalasia kongenital derajat sedang pada bayi dengan aspirasi rekuren, sehingga angka morbiditas dan mortalitas menurun.

Laporan kasus : Bayi perempuan, usia 2 bulan, konsulan dari bangsal anak RSUP Dr. Kariadi Semarang dirawat dengan assesment bronkopneumonia riwayat aspirasi rekuren, gizi buruk perawakan normal, dan anemia mikrositik normokromik. Diagnosis Bagian THT adalah laringmalasia kongenital derajat sedang disertai pneumonia aspirasi. Tatalaksanan dengan diit lewat NGT, medikamentosa, fisioterpi, stimulus oromotor. Evaluasi 1minggu mengalami perbaikan, dipulangkan terpasang NGT, diberi obat, edukasi, fisioterapi dan latihan stimulus oromotor Bayi. usia 6 bulan NGT di lepas. Evaluasi saat pasien berusia 8 bulan, tidak sesak nafas, minum susu dengan dot dan tidak tersedak.

Pembahasan : Laringomalasia dibagi menjadi derajat ringan, sedang dan berat. Laringomalasia derajat sedang perlu perbaikan gejala dengan memasang NGT untuk diit dan cegah aspirasi. 70\% bayi mengalami perbaikan setelah 12 bulan. 28\% laringomalasia derajat sedang dapat menjadi laringomalasia derajat berat. Bayi dengan laringomalasia derajat sedang dan saturasi oksigen ratarata $\leq 91 \%$ memerlukan terapi operatif (supraglottoplasti). Kasus ini terdiagnosis laringomalasia derajat sedang dengan terapi konservatif membaik dan tidak ada indikasi untuk dilakukan tindakan operatif.

Simpulan : Bayi perempuan 2 bulan terdiagnosis laringomalasia derajat sedang disertai aspirasi pneumonia. Diberikan tatalaksana konservatif mengalami perbaikan klinis. Usia 8 bulan tidak sesak, dapat minum dengan baik.
\end{abstract}

Kata kunci : Derajat laringomalasia, stridor, tatalaksana

\begin{abstract}
Background : Laryngomalacia is the most common congenital laryngeal disorder. The typical symptom of laryngomalacia is inspiratory stridor. Management of laryngomalacia is done with non-medication, medication, and operative management. The aim of writing this case is to report the management of moderategrade congenital laryngomalacia in infants with recurrent aspiration, so that the morbidity and mortality rates would be decreased.

Case report : 2 months old infant girl, consulted from the pediatric ward of Kariadi General Hospital, Semarang, assessed with bronchopneumonia, having history of recurrent aspiration, normal stature malnutrition, and microcytic normochromic anemia. Diagnosis from ENT department is moderate degree of congenital laryngmalacia accompanied by aspiration pneumonia. Treatment of the patient is dietary intake through NGT, medication, physiotherapy, and oromotor stimulation. After 1 week of evaluation, patient underwent improvement, and then, sent back home with NGT kept being inserted. Patient was given medication, education, physiotherapy and oromotor stimulation training. At the age of 6 months, NGT was released. Evaluation was done when the patient was 8 months old, and found no shortness of breath, patient could drink milk with a pacifier and did not choke.

Discussion : Laryngomalacia is divided into mild, moderate and severe degrees. Moderate degree of laryngomalacia needs management to improve symptoms by installing NGT for diet intake and preventing aspiration. $70 \%$ of infants get improvement after 12 months. $28 \%$ of moderate laryngomalacia can lead to severe degrees of laryngomalacia. Infants with moderate degrees of laryngomalacia and oxygen saturation on average $\leq 91 \%$ require operative therapy (supraglottoplasty). This patient was diagnosed with moderate grade of laryngomalasia improved after conservative therapy and there was no indication for operative surgery.
\end{abstract}


Conclusion : 2-months-old infant girl was diagnosed with moderate degree of laryngomalacia with aspiration pneumonia. Conservative management showed clinical improvement. At the age of 8 months, she did not have shortness of breath and could drink well.

Keywords : Degree of laryngomalacia, stridor, management.

\section{PENDAHULUAN}

Laringomalasia merupakan kelainan laring kongenital yang paling sering $(65-75 \%)$. Laringomalasia merupakan penyebab stridor pada bayi, yaitu $60-75 \% .{ }^{1-4}$ Laringomalasia biasanya bermanifestasi saat baru lahir atau usia beberapa minggu kehidupan. Gejala khas laringomalasia adalah stridor inspirasi, dapat intermitten, serta memburuk saat makan/minum, excitement, agitasi, menangis, dan posisi supinasi (tidur terlentang). Gejala laringomalasia yang lain yaitu serak atau afoni, dispneu, retraksi saat inspirasi pada sela supraklavikula, dan aspirasi rekuren. ${ }^{4,5}$ Bayi dengan laringomalasia sering dengan gejala yang ringan dan dapat sembuh sendiri saat usia 12-24 bulan. ${ }^{1,2}$

Laringomalasia dapat didiagnosis dari anamnesis, pemeriksaan fisik, serta pemeriksaan penunjang antara lain laringoskopi fleksibel dan fluoroskopi saluran nafas. Penatalaksanaan laringomalasia dapat diberikan dengan non medikamentosa, medikamentosa dan operatif. 2,6 Beratnya gejala dan faktor yang mempengaruhi keparahan penyakit perlu dilakukan tatalaksana dengan baik. Terapi operatif untuk laringomalasia adalah supraglottoplasti. ${ }^{2,6}$

Tujuan penulisan kasus ini adalah melaporkan tatalaksana laringomalasia kongenital derajat sedang pada bayi dengan aspirasi rekuren, sehingga angka morbiditas dan mortalitas menurun.

\section{LAPORAN KASUS}

Bayi perempuan, usia 2 bulan, konsulan dari bangsal anak RSUP Dr. Kariadi Semarang dirawat dengan assesment bronkopneumonia riwayat aspirasi rekuren curiga fistula trakeoesofagus, gizi buruk perawakan normal, dan anemia mikrositik normokromik.

Alloanamnesis dengan ibu, pasien sering tersedak saat minum sejak lahir, disertai sesak nafas, sesak nafas berkurang jika diposisikan miring dan tengkurap. Sesak nafas bertambah saat menangis dan minum. Nafas berbunyi sejak lahir. Pasien mengalami kesulitan saat menyusu. Pasien minum ASI sampai usia 2 minggu, lalu susu formula. Pasien dirawat inap sejak 1 hari yang lalu karena sesak nafas memberat, sudah diberi oksigen, obat suntik dan minum, sesak nafas sedikit berkurang, masih batuk, serta tidak demam.

Pasien anak pertama. Ibu berumur 28 tahun. Tidak ada riwayat konsumsi obat-obatan atau jamu saat kehamilan. Tidak terdapat riwayat demam. Ibu melahirkan ditolong oleh bidan saat usia kehamilan 36 minggu. Bayi lahir spontan, langsung menangis, tidak terdapat sesak, badan biru-biru, dan kuning. Berat badan bayi saat lahir 2650 gram. Perkembangan motorik normal sesuai usia. Pasien tidak terdapat riwayat trauma kepala dan alergi, serta belum pernah mendapatkan imunisasi karena sering sakit. Keluarga tidak terdapat riwayat penyakit serupa dan alergi.

Pemeriksaan fisik didapatkan keadaan umum rewel, nadi $138 \times$ /menit, intensitas dan tekanan kuat, RR (respiratory rate) $33 \times /$ menit, suhu $36,5^{\circ} \mathrm{C}$, saturasi oksigen $97-98 \%$, berat badan $3,5 \mathrm{~kg}$, stridor inspirasi, stridor berkurang dengan posisi miring, kepala mesosefal, dada terdapat retraksi epigastrial saat pasien menangis. Pulmo simetris statis dinamis, terdapat suara dasar vesikuler menurun dan ronki basah kasar pada paru kanan dan kiri. Pasien tidak terdapat wheezing dan tanda kelainan jantung, perut, serta ekstremitas. Pemeriksaan fisik telinga, hidung, dan tenggorok dalam batas normal. Hidung kanan terpasang NGT. Leher tidak terdapat pembesaran limfonodi.
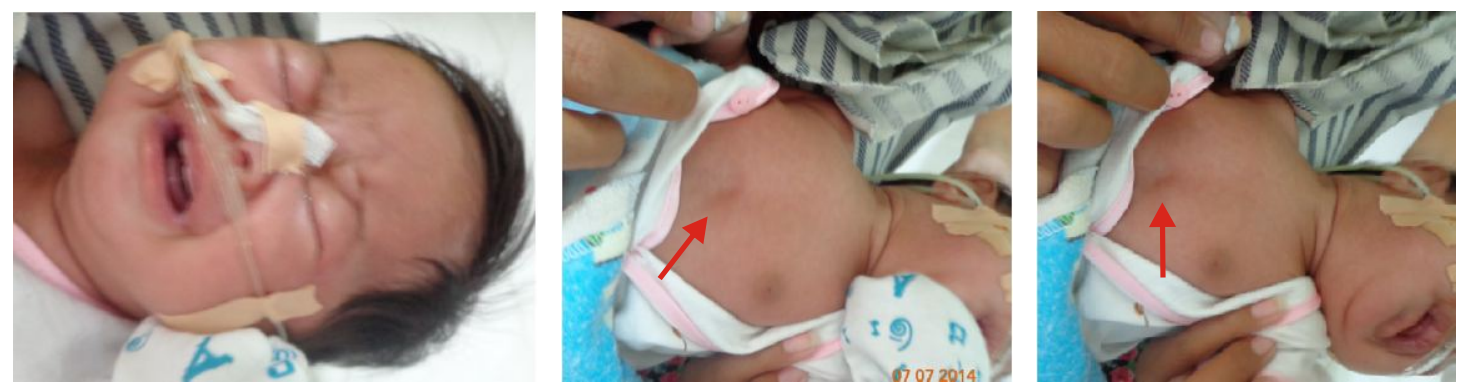

Gambar 1. Pemeriksaan fisik pasien 

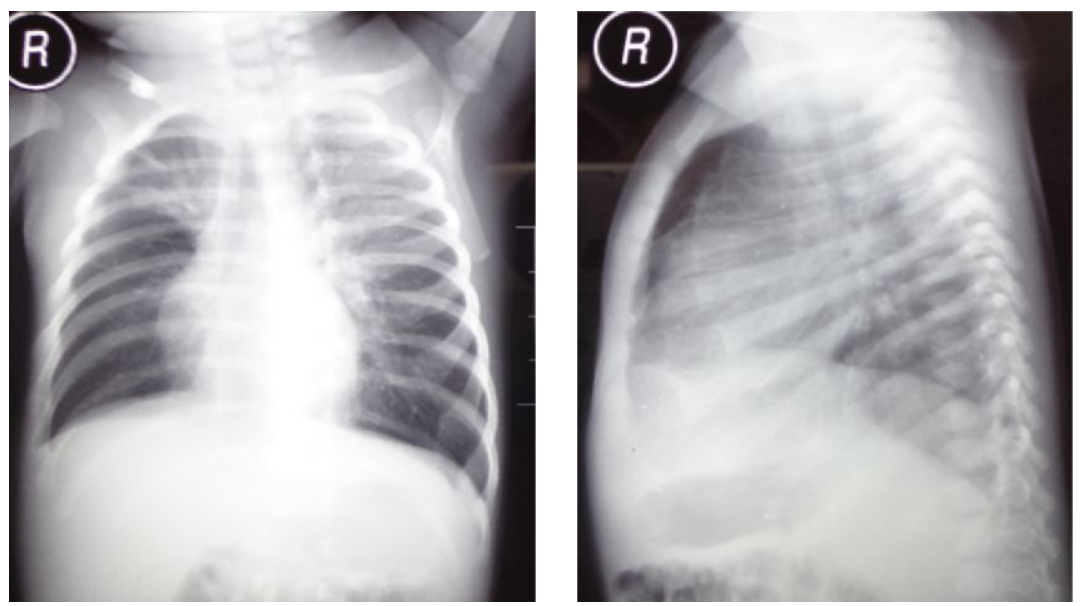

Gambar 2. X foto thoraks AP/lateral
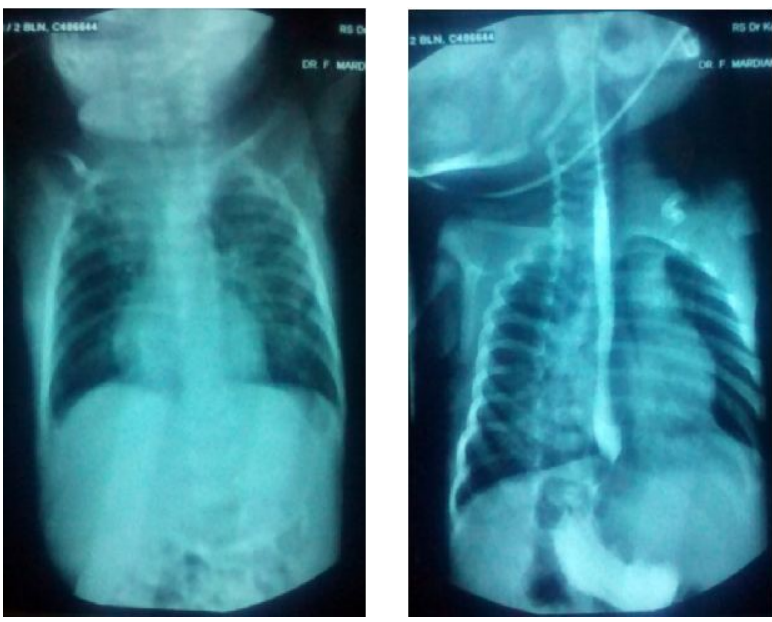

Gambar 3. Hasil pemeriksaan esofagografi

Hasil pemeriksaan laboratorium darah tanggal terdapat anemia $(9,3 \mathrm{~g} / \mathrm{dl})$ dan leukosit normal. Pemeriksaan sputum tanggal dengan hasil BTA negatif dan kultur terdapat Klebsiella pneumonia ssp pneumoniae yang sensitif terhadap meropenem, cefoperazone sulbactam, serta fosfomycin. Hasil pemeriksaan $X$ foto thoraks AP/lateral (Gambar 2) terdapat gambaran bronkopneumonia dan cor tidak membesar.

Bagian anak memberikan terapi $\mathrm{O}_{2}$ nasal 2 liter/menit, infus D5 1/2 NS 5 tetes per menit mikro, injeksi ampicillin $100 \mathrm{mg} / 6$ jam dan gentamisin $20 \mathrm{mg} /$ 24 jam intravena, asam folat $1 \mathrm{mg} / 24$ jam dan paracetamol sirup $30 \mathrm{mg} / 4-6$ jam per oral (jika suhu $\geq 38^{\circ} \mathrm{C}$ ), nebulizer berotec 4 tetes dicampur $\mathrm{NaCl} 0,9 \%$ $2 \mathrm{ml}$ tiap 12 jam, serta disuction setelah dinebulizer. Antibiotik ampicillin dan gentamisin dihentikan setelah hasil kultur jadi (7 hari), lalu diganti injeksi meropenem $50 \mathrm{mg} / 8$ jam intravena (skin test dulu) selama 7 hari. Pengawasan keadaan umum, tanda vital, distres respirasi, acceptabilitas diet, balance cairan dan diuresis tiap 24 jam, posisi miring/tengkurap jika sesak atau menangis, suction rutin tiap 6 jam serta sebelum dan setelah nebulizer, diet susu F $758 \times 60$ ml, esofagografi, kejar imunisasi, serta konsul departemen Rehabilitasi Medik dan departemen Bedah Thoraks vaskuler.

Diagnosis pasien ini laringomalasia kongenital derajat sedang, gejala dan tanda fistel trakeoesofagus saat ini belum dapat disingkirkan. Hasil konsulan Rehabilitasi Medik didapatkan hipersekresi dan retensi sputum, refleks menghisap negatif, dan disarankan fisioterapi (drainase postural dan gentle tapotage) serta terapi stimulasi (latihan stimulasi oromotor) setiap hari. Hasil konsulan bedah didapatkan laringomalasia derajat sedang dengan diagnosis banding fistula trakeoesofagus, disarankan esofagografi. Gambaran esofagogram (Gambar 3) tidak tampak gambaran fistula trakeoesofagus, terdapat gambaran pneumonia.

Evaluasi $2 \mathrm{mg}$, kondisi pasien membaik, diet tidak terdapat residu, balance cairan seimbang, dan sesak nafas berkurang, kemudian terapi oksigen dikurangi secara bertahap. Pasien tidak demam selama perawatan, dipulangkan dengan terpasang NGT no.5, berat badan 
(BB) $3,5 \mathrm{~kg}$, dan mendapat terapi pulang amoxilin 2,5 ml/8 jam dan salbutamol 0,4 mg/8 jam puyer per oral, kontrol 1 minggu.

Edukasi diberikan kepada keluarga pasien, meliputi:

- Pasien jika sesak nafas maka diposisikan miring atau tengkurap.

- Diet melalui NGT dengan posisi tegak saat minum.

- Diet hanya ASI saja sampai usia 6 bulan, kalau tidak mencukupi dapat ditambah susu formula.

- Fisioterapi dan latihan/stimulasi oromotor secara teratur.

- Kontrol teratur di Bagian Anak, ganti NGT tiap 14 hari.

- Pasien jika sesak nafas memberat dan tidak membaik dengan perubahan posisi maka segera periksa ke IGD (Instalasi Gawat Darurat).

- Pasien segera diperiksakan jika batuk/pilek agar tidak memperberat sesak nafas.

Pasien kontrol pertama saat berusia 4 bulan dengan kondisi perbaikan, batuk berkurang, Ronki pada lapangan paru berkurang, BB 3,7 kg, diberi terapi oleh TS Bagian Anak dengan salbutamol 0,3 mg dan methyl prednisolone $1 \mathrm{mg}$ puyer tiap 8 jam, NGT dilepas dan diganti yang baru. Reflek menghisap pada pasien ada lagi setelah dilakukan terapi/latihan oral motor yang dilakukan oleh terapis wicara.

Saat kontrol ulang pasien usia 6 bulan NGT dilepas, Evaluasi saat pasien berusia 8 bulan, tidak sesak nafas, minum susu dengan dot dan tidak tersedak.

\section{PEMBAHASAN}

Laringomalasia adalah suatu kelainan dimana terjadi kelemahan struktur supraglotis (epiglotis dan kartilago aritenoid) yaitu lembek dan lentur sehingga saluran nafas menjadi kolaps menuju ke dalam dan terjadi obstruksi pada saat inspirasi serta dapat terjadi aspirasi rekuren. Aliran udara melalui saluran nafas yang obstruksi menyebabkan stridor. ${ }^{1-3}$

Holinger meneliti pada 219 pasien dengan stridor, kelainan kongenital pada laring menempati urutan pertama $(60,3 \%)$. Penyebab stridor tersering pada bayi ialah laringomalasia kongenital (65-75\%). Aspirasi rekuren terjadi pada $100 \%$ bayi dengan laringomalasia. ${ }^{4}$ Kejadian laringomalasia pada laki-laki dua kali lebih banyak dari pada perempuan. . $, 3,5^{2}$

Diagnosis laringomalasia dapat ditegakkan dari anamnesis, pemeriksaan fisik, dan pemeriksaan penunjang yaitu laringoskopi fleksibel dan fluoroskopi saluran nafas. Gejala khas laringomalasia adalah terdapat stridor inspirasi bernada tinggi, dapat intermitten, yang memburuk saat makan/minum, menangis, excitement, posisi terlentang, dan agitasi. Gejala laringomalasia yang lain yaitu serak, dispneu, retraksi saat inspirasi pada sela supraklavikula, dan aspirasi rekuren. ${ }^{5,6}$ Gejala dapat dimulai sejak lahir atau dalam beberapa minggu pertama kehidupan, biasanya dalam 2-3 minggu pertama kehidupan, mencapai puncak saat usia 6-8 bulan, dan biasanya sembuh sendiri saat usia 12-24 bulan, yaitu saat kartilago laring menjadi rigid. Laringomalasia sering terdiagnosis saat 3-4 bulan pertama kehidupan. ${ }^{2,5,6}$

Kasus ini bayi usia 2 bulan dengan laringomalasia kongenital dan aspirasi rekuren, terdapat keluhan sering tersedak saat minum sejak lahir, disertai sesak nafas karena batuk-batuk setelah tersedak, sesak nafas berkurang jika diposisikan miring dan lebih berkurang lagi jika diposisikan tengkurap. Sesak nafas bertambah saat menangis dan minum. Pasien mengalami kesulitan saat menyusu dan menyusu lebih lama. Dari pemeriksaan terdapat stridor inspirasi yang memberat saat pasien menangis, retraksi epigastrial saat pasien menangis, serta stridor dan retraksi berkurang saat pasien posisi tengkurap.

Laringomalasia dibagi menjadi 3 stadium, yaitu ringan, sedang, dan berat. Pembagian stadium ini berdasarkan gejala yang berhubungan dengan makan/minum dan gejala obstruktif. Laringomalasia derajat ringan jika terdapat stridor inspirasi ringan, yang kadang-kadang terdapat gejala yang berhubungan dengan makan/minum yaitu batuk, tersedak, dan regurgitasi. Laringomalasia derajat ringan terdapat pada $40 \%$ bayi. Laringomalasia derajat ringan terdapat stridor inspirasi yang kadang-kadang terdapat gejala yang berhubungan dengan makan/minum yaitu batuk, tersedak, dan regurgitasi. Koordinasi menghisap, menelan, dan bernafas secara berurutan baik dan dapat makan dengan tenang. Obstruksi saluran nafas tidak menyebabkan terjadi hipoksia. Saturasi oksigen rata-rata saat istirahat $98-100 \% .2,7$

Tujuh puluh persen bayi dengan laringomalasia derajat ringan dapat membaik dan sembuh. Tiga puluh persen bayi dengan laringomalasia derajat ringan yang mengalami gejala refluks akan memburuk, dan menjadi laringomalasia derajat sedang. Laringomalasia derajat ringan dengan gejala yang berhubungan dengan refluks, dengan saturasi oksigen rata-rata $\leq 96 \%$ dapat menjadi laringomalasia derajat sedang., ${ }^{2,7}$

Laringomalasia derajat sedang jika sering terdapat stridor yang berhubungan dengan makan/minum. Empat puluh persen bayi dengan laringomalasia merupakan laringomalasia derajat sedang, dimana terdapat stridor yang khas, bayi rewel dan sulit makan. Sering terjadi gejala yang berhubungan dengan makan/minum, yaitu batuk, tersedak, regurgitasi, dan sianosis saat makan/minum. Laringomalasia derajat sedang jika tidak terdiagnosis dan tidak diterapi maksimal, maka dapat terjadi aspirasi, berat badan menurun, dan sulit makan/minum. Tindakan untuk memperbaiki gejala yang berhubungan dengan makan/minum antara lain modifikasi tekstur makanan dengan mengkentalkan susu formula atau ASI 


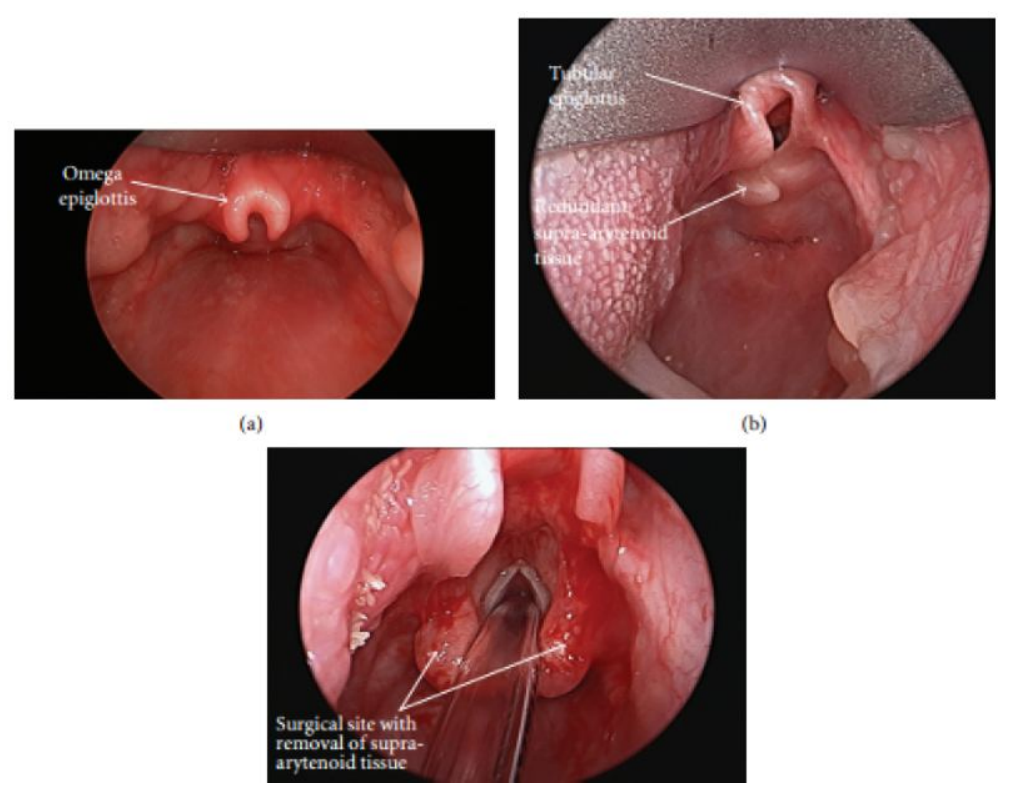

Gambar 4. (a) Epiglotis berbentuk omega. (b) Epiglotis berbentuk tubuler sepanjang jaringan supra-aritenoid yang mengalami obstruksi selama inspirasi. (c) Lokasi redundant jaringan supra-aritenoid setelah operasi. ${ }^{2}$

(air susu ibu), posisi tegak saat minum, dan memasang NGT (Class IIa, Level of Evidence B). 2,7,8 Tujuh puluh dua persen bayi mengalami perbaikan setelah 12 bulan terapi supresi asam. Bayi dengan laringomalasia derajat sedang tidak mengalami hipoksia, saturasi oksigen rata-rata 96-98\%. Dua puluh delapan persen laringomalasia derajat sedang dapat menjadi laringomalasia derajat berat walaupun sudah dimodifikasi makan dan terapi supresi asam, sehingga perlu dipantau. Bayi dengan laringomalasia derajat sedang dan saturasi oksigen ratarata $\leq 91 \%$ lebih memerlukan terapi operasi, biasanya supraglottoplasti (Class IIa, Level of Evidence B)., 2,8

Laringomalasia derajat berat jika stridor dan gejala obstruksi yang berhubungan dengan makan/minum selalu ada dan berat. Dua puluh persen bayi menderita laringomalasia berat. Gejala laringomalasia berat yaitu terdapat sianosis yang rekuren, terdapat fase apneu, sulit makan, aspirasi, gagal tumbuh, retraksi suprasternal dan subcostal, sampai pectus excavatum. Saturasi oksigen ratarata $86 \% .2,7,9$ Laringomalasia berat jika tidak terdiagnosis dan diterapi dengan baik, maka akan terjadi hipoksia kronik, sehingga dapat terjadi hipertensi pulmonal dan cor pulmonal. Terapi operasi dengan supraglottoplasti dengan mengambil jaringan kolaps yang menyebabkan obstruksi dengan menggunakan endoskopi. Trakeotomi jarang diindikasikan, dan dilakukan jika supraglottoplasti gagal dan dengan multipel komorbid (Class IIa, Level of Evidence B). 2,7,8

Pemeriksaan penunjang untuk mendiagnosis laringomalasia antara lain laringoskopi fleksibel. Jaringan supraglotik yang kolaps dan mengalami obstruksi selama inspirasi merupakan tanda khas laringomalasia, hal ini terjadi karena plika ariepiglotika memendek, bagian posterior kartilago aritenoid prolaps dan mukosa mengarah ke dalam saluran nafas selama inspirasi, atau melekuknya epiglotis ke arah posterior (retrofleksi) atau berbentuk omega (Gambar 4). 2,10

Pasien pada kasus ini belum dilakukan pemeriksaan laringoskopi fleksibel karena mengalami perbaikan setelah terapi konservatif dengan medikamentosa dan fisioterapi, kemudian pasien dipulangkan, direncanakan program laringoskopi fleksibel saat kontrol 1 bulan lagi bila hasil terapi medikamentosa dan fisioterapi tidak maksimal.

Terapi operatif diindikasikan pada laringomalasia derajat berat, dengan stridor, kelainan respiratori, kelainan saat makan/minum, dan gagal tumbuh (Class IIa, Level of Evidence A). Obstruksi saluran nafas berat dengan retraksi berat, pectus excavatum, cor pulmonal, hipertensi pulmonal, dan hipoksia merupakan indikasi absolut untuk dilakukan tindakan operasi (Class IIa, Level of Evidence A). Indikasi relatif operasi adalah aspirasi dengan pneumonia rekuren, berat badan menurun tanpa gagal tumbuh, dan kelainan yang berhubungan dengan makan/minum yang tidak respon terhadap terapi supresi asam (Class IIa, Level of Evidence B). Tujuan operasi adalah untuk meningkatkan derajat kesehatan dan tumbuh kembang anak. Supraglottoplasti merupakan terapi operasi untuk laringomalasia.,11 Pasien dalam anestesi umum, saluran nafas pertama dievaluasi dengan endoskopi rigid (microdirect laryngoscopy dan bronchoscopy) menyingkirkan lesi di subglotis dan trakea. Supraglotis dievaluasi saat respirasi spontan, dan jika terdapat daerah yang kolaps diperhatikan. Laring 


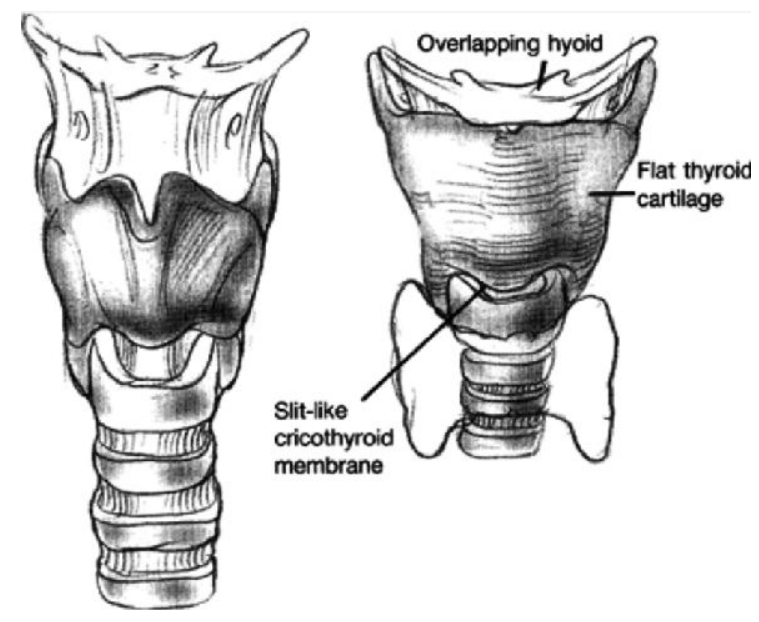

Gambar 5. Kartilago tiroid bayi mendatar dan overlap dengan tulang hioid (bagian atas) dan kartilago krikoid (bagian bawah) ${ }^{14}$

dievaluasi dengan laringoskop, kemudian dilakukan supraglottoplasti untuk mengambil mukosa aritenoid yang berlebihan. ${ }^{2}$

Jenis operasi yang dilakukan pada laringomalasia adalah supraglottoplasti yang memiliki sinonim epiglottoplasti dan ariepiglottoplasti. Berdasarkan klasifikasi Olney terdapat tiga teknik supraglottoplasti yang dapat dilakukan. Teknik yang dipilih tergantung pada kelainan laringomalasianya. ${ }^{12,13}$

Keberhasilan operasi supraglottoplasti sekitar 94\%, dengan komplikasi yang rendah (Class IIa, Level of Evidence A). Supraglottoplasti revisi atau trakeostomi dibutuhkan pada $19-45 \%$ bayi dan tergantung pada jumlah dan tipe komorbid yang menyertai (Class IIa, Level of Evidence B). Trakeostomi diperlukan pada pasien yang mengalami obstruksi saluran nafas yang mengancam nyawa secara terus-menerus dan tidak membaik setelah supraglottoplasti (Class IIa, Level of Evidence A). ${ }^{2}$

Kartilago tiroid bayi mendatar dan overlap dengan tulang hioid (bagian atas) dan kartilago krikoid (bagian bawah), yang dengan bertambahnya usia akan semakin terpisah, sehingga bayi dengan laringomalasia sedang atau berat yang tidak membaik dengan perubahan posisi, direkomendasikan dipasang intubasi endotrakeal, karena kalau dilakukan trakeostomi atau krikotiroidotomi akan kesulitan mencari landmark (Gambar 5). ${ }^{14}$

Pasien ini tidak dilakukan terapi operatif karena mengalami perbaikan dengan terapi medikamentosa dengan diet melalui NGT dan fisioterapi (Class IIa, Level of Evidence B).

\section{SIMPULAN}

Telah dilaporkan bayi perempuan berusia 2 bulan dengan diagnosis laringomalasia kongenital derajat sedang dengan aspirasi rekuren. Aspirasi rekuren menyebabkan terjadinya bronkopneumonia. Pasien dilakukan penatalaksanaan medikamentosa dan terapi/latihan stimulasi oral motor membaik, dengan diet melalui NGT. Penatalaksanaan laringomalasia secara komprehensif/multidisiplin sangat diperlukan untuk keberhasilan terapi.

\section{DAFTAR PUSTAKA}

1. Lauren DH. Congenital Anomalies of the larynx, trachea, and bronchi. In: Behrman RE, Kliegman RM, Schor NF, Stanton BF, Geme III JWS, editors. Nelson textbook of pediatrics. $19^{\text {th }}$ ed, Philadelphia: Elsevier Saunders; 2011. P. 1450-2.

2. Landry AM, Thompson DM. Laryngomalacia: disease presentation, spectrum, and management. International Journal of Pediatrics. 2012:1-6.

3. Probst R, Grevers G, Iro. Malformation of the larynx and trachea. In : Basic otorhinolaryngology. $2^{\text {nd }}$ ed. Stuttgart: Georg Thieme; 2006.P.350-3.

4. Bilan N, Behbahan AG, Miabi Z. Diagnosis of airway malacia by virtual bronchoscopy. Pakistan Journal of Biological Sciences. 2008;11(14):1881-3.

5. Huntley C, Carr MM. Evaluation of effectiveness of airway fluoroscopy in diagnosing patients with laryngomalacia. Laryngoscope. 2010; 120:1430-3.

6. Manaligod JM. Does reflux have a causative role in laryngomalacia?. Otolaryngology. 2013;3(3):1-4.

7. Thompson DM. Laryngomalacia: factors that influence disease severity and outcomes of management. Current Opinion in Otolaryngology \& Head and NeckSurgery. 2010; 18:564-70.

8. Ayari, S. et al. Management of laryngomalacia. Eur. Ann. Otorhinolaryngol. Head Neck Dis. 130, 15-21 (2013).

9. Lusk R. Congenital anomalies of the larynx. In: SnowJB, editor. Otorhinolaryngology head and neck surgery. Ontario: BC Decker Inc; 2003. P. 1049-51.

10. Pinto, J. A., Wambier, H., Mizoguchi, E. I. \& Gomes, L. M. Surgical treatment of severe laryngomalacia: a retrospective study of 11 cases. 79, 564-568 (2013).

11. Schroeder JW, Bhandarkar ND, Holinger LD. Synchronous airway lesions and outcomes in infants with severe 
laryngomalacia requiring supraglottoplasty. Arch Otolaryngol Head Neck Surg. 2009;135(7):647-651.

12. Olney DR, Greinwald JH, Smith RJ. Laryngomalacia and its treatment. Laryngoscope. 1999; 109:1770-5.

13. Rawring BA, Derkay CS, Chu MW. Surgical treatment of laryngomalacia. Operative Tech in Otolaryngol. 2009; 20: 222-8.
14. Cunningham MJ. Pediatric Otolaryngology. In: Bailey BJ, Johnson JT, editors. Head and neck surgery-otolaryngology. $4^{\text {th }}$ ed. Vol I. Philadelphia: Lippincott Williams and Wilkins; 2006. P.1047-61. 